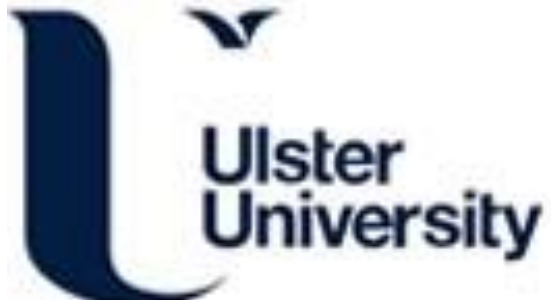

\section{Patterns of presentation for attempted suicide: analysis of a cohort of individuals who subsequently died by suicide}

Mallon, S., Rosato, M., Galway, K., Hughes, L., Rondon-Sulbaran, J., McConkey, S., \& Leavey, G. (2014). Patterns of presentation for attempted suicide: analysis of a cohort of individuals who subsequently died by suicide. Suicide and Life-Threatening Behaviour, 45(3), 335-344. https://doi.org/10.1111/sltb.12134

Link to publication record in Ulster University Research Portal

\section{Published in:}

Suicide and Life-Threatening Behaviour

Publication Status:

Published (in print/issue): 01/01/2014

DOI:

10.1111/sltb.12134

\section{Document Version}

Publisher's PDF, also known as Version of record

\section{General rights}

Copyright for the publications made accessible via Ulster University's Research Portal is retained by the author(s) and / or other copyright owners and it is a condition of accessing these publications that users recognise and abide by the legal requirements associated with these rights.

\section{Take down policy}

The Research Portal is Ulster University's institutional repository that provides access to Ulster's research outputs. Every effort has been made to ensure that content in the Research Portal does not infringe any person's rights, or applicable UK laws. If you discover content in the Research Portal that you believe breaches copyright or violates any law, please contact pure-support@ulster.ac.uk. 


\title{
Patterns of Presentation for Attempted Suicide: Analysis of a Cohort of Individuals Who Subsequently Died by Suicide
}

\author{
Sharon Mallon, PhD, Michael Rosato, PhD, Karen Galway, PhD, Lynette \\ Hughes, PhD, Janeet Rondon-Sulbaran, MSc, Sam McConkey, BSc, and Gerard \\ Leavey, PhD
}

\begin{abstract}
All suicides and related prior attempts occurring in Northern Ireland over two years were analyzed, focusing on number and timing of attempts, method, and mental health diagnoses. Cases were derived from coroner's records, with $90 \%$ subsequently linked to associated general practice records. Of those included, $45 \%$ recorded at least one prior attempt (with 59\% switching from less to more lethal methods between attempt and suicide). Compared with those recording one attempt, those with $2+$ attempts were more likely to have used less lethal methods at the suicide $(\mathrm{OR}=2.77$ : $95 \% \mathrm{CI}=1.06,7.23)$; and those using less lethal methods at the attempts were more likely to persist with these into the suicide $(\mathrm{OR}=3.21: 0.79,13.07)$. Finally, those with preexisting mental problems were more likely to use less lethal methods in the suicide: severe mental illness $(\mathrm{OR}=7.88$ : $1.58,39.43)$; common mental problems $(\mathrm{OR}=3.68$ : $0.83,16.30)$; and alcohol/drugs related $(\mathrm{OR}=2.02: 0.41,9.95)$. This analysis uses readily available data to highlight the persisting use of less lethal methods by visible and vulnerable attempters who eventually complete their suicide. Further analysis of such conditions could allow more effective prevention strategies to be developed.
\end{abstract}

Reducing suicide is a significant public health challenge. Known risk factors have long included socioeconomic deprivation and worklessness (Lewis \& Sloggett, 1998; Moser, Fox, \& Jones, 1984; O’Reilly, Rosato,
Connolly, \& Cardwell, 2008), male gender (Canetto \& Cleary, 2012; Shiner, Scourfield, Fincham, \& Langer, 2009), age (Mok et al., 2012), and psychiatric illness (Carlsten, Waern, Ekedahl, \& Ranstam, 2001;
Sharon Mallon, Open University, Milton Keynes, UK; MichaEl Rosato, Bamford Centre for Mental Health and Wellbeing, University of Ulster, Derry, UK; Karen GaLwaY, Queens University, Belfast, UK; LYNETTE Hughes, Janeet Rondon-Sulbaran, and Sam McConkeY, Northern Ireland Association for Mental Health (NIAMH), Belfast, UK; GERARD Leavey, Bamford Centre for Mental Health and Wellbeing, University of Ulster, Derry, UK.

The authors thank the Coroner's Service for Northern Ireland and Health \& Social Care Business Services Organisation (HSC-BSO) for their help in accessing the data. We also thank
NIAMH (Northern Ireland Association for Mental Health) for their support. The analysis and opinions expressed are the views of the authors. The funders and those providing access to data had no role in study design, analysis, decision to publish, or preparation of the manuscript.

This research was funded by the $R \& D$ Division of the Public Health Agency for Northern Ireland.

Address correspondence to Michael Rosato, Bamford Centre for Mental Health and Wellbeing, University of Ulster, Derry, UK; E-mail: mg. rosato@ulster.ac.uk 
Oquendo et al., 2003). Genetic markers have also been associated with suicide ideation (Laje et al., 2007), and latterly, it has been suggested that epigenetic mechanisms may play a role in attempted suicide (Murphy et al., 2013). Importantly, suicide is considered by some as preventable (Wheller, Baker, Griffiths, \& Rooney, 2007). However, while many of its indicators are pervasive, suicide remains relatively rare, and it has been suggested that such risk factors have only limited predictability when applied to individual cases (Beautrais, 2004; Caine, 2010). For example, for every suicide death, there are 25 nonfatal attempts (Maris, Berman, \& Silverman, 2000). Therefore, while prior attempts can predict eventual suicide, increasing risk by $10 \%$ to 15\% (Cederecke \& Ojehagen, 2005; Cullberg, Wasserman, \& Stefansson, 1988; Maris, 1992), reliance on it as a predictor is not realistic (Owens, Horrocks, \& House, 2002). Nevertheless, readily available information relating to prior suicide behavior may be useful in developing prevention strategies sufficiently targeted to both predict and respond to those likely to be at greatest risk.

Consequently, focus has shifted to identifying characteristics that might distinguish people at particularly high risk following attempted suicide. Studies have examined the length of time an individual remains at risk after an attempt: one Finnish study found that $44 \%$ of suicides had recorded prior attempts-19\% in the 12 months prior to death (Isometsa \& Lonnquist, 1998). Research has also examined the characteristics of the suicide method, with elevated risk of eventually completing suicide indicated through use of more lethal methods (Isometsa \& Lonnquist, 1998) and increasing severity of poisoning (Carter, Reith, Whyte, \& McPherson, 2005; Runeson, Tidemalm, Dahlin, Lichenstein, \& Langstrom, 2010). Such information may help develop better-targeted prevention efforts; for example, in monitoring sequential admission patterns for self-poisoning (Runeson et al., 2010) or intensified after- care (Isometsa \& Lonnquist, 1998). There is little research on the patterning of methods used in suicide attempts and the temporal relation of these attempts to eventual suicide. In this paper we explore both this temporal patterning of prior attempts (including their number and timing, and methods used) and the persistence of less lethal methods across multiple attempts.

\section{METHOD}

This is a retrospective study of all deaths in Northern Ireland (NI) determined to be suicide by the NI Coroner Service (NICS) between March 1, 2007, and February 28, 2009. Data were extracted and collated between January and November 2011 from two sources: coroner records and associated general practitioner (GP) medical records. Permission to access the data was granted using the "research exemption," Section 33 of the Data Protection Act. Ethical approval was obtained from the NI branch of the UK Office for Research Ethics Committee (ORECNI).

Data relating to suicide attempts were extracted from the GP record: it was possible to report only on acts of self-injury resulting in either attendance with medical practitioners or at hospital emergency departments. Distinguishing between a failed attempt and a suicide gesture is difficult (Williams, 1997). The definition of suicide attempt used here is "an act with nonfatal outcome, in which an individual deliberately initiates a nonhabitual behavior that, without intervention from others, will cause self-harm, or deliberately ingests a substance in excess of the prescribed or generally recognized therapeutic dosage and which is aimed at realizing changes which the subject desired via the actual or expected physical consequences" (Kerkhof, Schmidtke, BilleBrahe, \& Lonnqvist,, 1994).

The data were collected by two researchers. To ensure interrater reliability, a cross sample of ten cases was compared. While data relating to suicide attempts were 
largely extracted from information sent to GPs by doctors working in emergency departments, some were obtained from related psychiatric reports. These detailed both presentation at hospital following an instance of deliberate self-harm and any related assessments made or treatments given. The summary methods used for the analysis included reclassification into lethal or less lethal types, and draws on both the Runeson et al., (2010) study and the Harvard School of Public Health (2013) assessment of lethality. To derive these, we have taken a pragmatic view and in aggregating the specific methods used included wider elements of intent, lethality, and prospective finality or fatality in the classification: lethal methods include hanging, gunshot, and jumping; less lethal methods include drugs overdose, poisoning, drowning, cutting, and asphyxiation by gassing.

Other indicators related to the attempt include time from last prior attempt to the completed suicide (dichotomized into less than a year, and one or more years); number of prior attempts (dichotomized as either one attempt, or two or more); and level of lethality of method. Finally, already diagnosed preexisting mental health problems were included for analysis and summarized into three groups: (1) common mental bealth problems included depression, anxiety, phobias, stress, psychological disorders, and posttraumatic stress disorder (PTSD); (2) severe mental illness comprised schizophrenia, psychosis, bipolar disorder, and personality disorders; and (3) alcohol/drugs problems included those with alcohol and/or drug dependency problems. However, some misclassification is possible, because some mental disorders could have remained undiagnosed.

\section{RESULTS}

Over the study period, 403 suicides were recorded by the NICS (325 males and 78 females). Of these, 42 sets of GP records were missing (34 males and 8 females): 14 were not registered with a GP, and 28 sets of medical records were unavailable. These were excluded from analysis. The study population comprised 291 male and 70 female suicides; their ages ranged from 11 to 83 (mean 39.6 and $S D=16.189$ ). There was no significant age difference between males and females.

Of those with a medical record, $44.0 \%(159 / 361)$ were treated by a medical practitioner at some point in relation to a suicide attempt; therefore, 56.0\% (202/361) died at their first attempt, with males recording $86.1 \%(174 / 202)$ of those deaths $\left(\chi^{2}=8.970 p=.003\right)$. However, while males comprised $74 \%(117 / 159)$ of suicides following a prior attempt, among females $60 \%$ (42/70) of completed suicides were preceded by an attempt, compared to $40 \%$ (117/291) for males (see Table 1).

The number of attempts by age group is also outlined in Table 1. Among males, a single attempt was recorded for $53 \%(62 / 117)$ and $47 \%(55 / 117)$ made two or more attempts. Older males ( $>35$ years) were more likely to have recorded a single attempt, and younger males $(<35)$ more likely to record two or more. Multiple attempts were recorded for $63 \%(12 / 19)$ of males aged less than 25. A preferential accumulation of prior attempts by females shows in the age distribution. Among females aged 35 to 64 , more than $70 \%$ within each age group recorded a history of attempts. For males 25 to 64 , the comparable proportions were less than $50 \%$. Generally, the youngest and oldest age groups were less visible in this respect, with both less likely to have recorded a previous attempt.

While for $55.4 \%(88 / 159)$ of cases the final attempt occurred more than a year before the completed suicide, for $10.7 \%$ (17/ 159) the attempt occurred in the 30 days before the completed suicide (Table 1), with males comprising $88.2 \%(15 / 17)$ of this group. However, while with males the proportions increased in those aged 25 to 64 (rising from 6\% to 20\%), in the youngest age group (<25 years) $68.3 \%(13 / 22)$ made 
TABLE 1

Completed Suicides in Northern Ireland (March 2007-February 2009): Prior Suicide Attempts by Age Group and Gender (Data Represent Percentages and Numbers)

\begin{tabular}{|c|c|c|c|c|c|c|c|}
\hline & $<25$ & $25-34$ & $35-44$ & $45-54$ & $55-64$ & $65+$ & Total \\
\hline \multicolumn{8}{|l|}{ Males } \\
\hline Prior attempts $=$ no & $66.1(37)$ & $52.9(37)$ & $56.4(31)$ & $63.2(36)$ & $51.6(16)$ & $77.3(17)$ & $59.8(174)$ \\
\hline Prior attempts $=$ yes & $33.9(19)$ & $47.1(33)$ & $43.6(24)$ & $36.8(21)$ & $48.4(15)$ & $22.7(5)$ & $40.2(117)$ \\
\hline \multicolumn{8}{|l|}{ Prior attempts } \\
\hline 1 recorded & $36.8(7)$ & $48.4(16)$ & $50.0(12)$ & $57.1(12)$ & $66.7(10)$ & $100.0(5)$ & $53.0(62)$ \\
\hline 2 or more & $63.1(12)$ & $51.5(17)$ & $50.0(12)$ & $42.9(9)$ & $33.3(5)$ & $0.0(0)$ & $47.1(55)$ \\
\hline \multicolumn{8}{|l|}{ Final attempt } \\
\hline$<30$ days before & $15.8(3)$ & $6.1(2)$ & $12.5(3)$ & $19.1(4)$ & $20.0(3)$ & $0.0(0)$ & $12.8(15)$ \\
\hline Less than 1 year & $68.3(13)$ & $45.4(15)$ & $45.8(11)$ & $38.1(8)$ & $40.0(6)$ & $20.0(1)$ & $46.2(54)$ \\
\hline $1+$ years & $31.6(6)$ & $54.6(18)$ & $54.2(13)$ & $61.9(13)$ & $60.0(9)$ & $80.0(4)$ & $53.9(63)$ \\
\hline \multicolumn{8}{|l|}{ Females } \\
\hline Prior attempts $=$ no & $73.3(11)$ & $44.4(4)$ & $28.6(6)$ & $21.4(3)$ & $25.0(1)$ & $42.9(3)$ & $40.0(28)$ \\
\hline Prior attempts $=$ yes & $26.7(4)$ & $55.6(5)$ & $71.4(15)$ & $78.6(11)$ & $75.0(3)$ & $57.1(4)$ & $60.0(42)$ \\
\hline \multicolumn{8}{|l|}{ Prior attempts } \\
\hline 1 recorded & $50.0(2)$ & $40.0(2)$ & $26.7(4)$ & $27.3(3)$ & $100.0(3)$ & $50.0(2)$ & $38.1(16)$ \\
\hline 2 or more & $50.0(2)$ & $60.0(3)$ & $73.3(11)$ & $72.7(8)$ & $0.0(0)$ & $50.0(2)$ & $61.9(26)$ \\
\hline \multicolumn{8}{|l|}{ Final attempt } \\
\hline$<30$ days before & $0.0(0)$ & $20.0(1)$ & $6.7(1)$ & $0.0(0)$ & $0.0(0)$ & $0.0(0)$ & $4.8(2)$ \\
\hline Less than 1 year & $25.0(1)$ & $40.0(2)$ & $46.7(7)$ & $18.2(2)$ & $100.0(3)$ & $50.0(2)$ & $40.5(17)$ \\
\hline $1+$ years & $75.0(3)$ & $60.0(3)$ & $53.3(8)$ & $81.8(9)$ & $0.0(0)$ & $50.0(2)$ & $59.5(25)$ \\
\hline \multicolumn{8}{|l|}{ Persons } \\
\hline Prior attempts $=$ no & $67.6(48)$ & $51.9(41)$ & $48.7(37)$ & $55.9(39)$ & $48.6(17)$ & $69.0(20)$ & $56.0(202)$ \\
\hline Prior attempts $=$ yes & $32.4(23)$ & $48.1(38)$ & $51.3(39)$ & $44.1(32)$ & $51.4(18)$ & $31.0(9)$ & $44.0(159))$ \\
\hline \multicolumn{8}{|l|}{ Prior attempts } \\
\hline 1 recorded & $39.1(9)$ & $47.4(18)$ & $41.0(16)$ & $46.9(15)$ & $72.2(13)$ & $77.8(7)$ & $49.1(78)$ \\
\hline 2 or more & $60.8(14)$ & $53.3(20)$ & $59.0(23)$ & $43.2(17)$ & $27.8(5)$ & $22.2(2)$ & $51.0(81)$ \\
\hline \multicolumn{8}{|l|}{ Final attempt } \\
\hline$<30$ days before & $13.0(3)$ & $7.9(3)$ & $10.3(4)$ & $12.5(4)$ & $16.7(3)$ & $0.0(0)$ & $10.7(17)$ \\
\hline Less than 1 year & $60.9(14)$ & 44.7 (17) & $46.2(18)$ & $31.3(10)$ & $50.0(9)$ & $33.3(3)$ & $44.6(71)$ \\
\hline $1+$ years & $39.1(9)$ & $55.3(21)$ & $53.9(21)$ & $68.8(22)$ & $50.0(9)$ & $66.7(6)$ & $55.4(88)$ \\
\hline
\end{tabular}

the attempt within a year. While numbers recorded for the shortest time period are low, they at least give an idea of the timing. Other more narrowly defined time periods tested did not warrant specific inclusion; for example, $0.4 \%(7 / 159)$ and $0.6 \%(10 / 159)$ made their final attempt less than 7 and 14 days, respectively, before the completed suicide.

The relationship between the methods used (dichotomized as lethal and less lethal) in the completed suicide and its immediately prior attempt are shown in Table 2. Columns 2 and 3 record both the proportions of attempts and completed suicides classed as lethal: for males, $20.5 \%$ and $82.1 \%$, respectively, were classed as lethal; for females, the comparable figures are $17.1 \%$ and $66.7 \%$. The final column shows the net shift from less to more lethal methods between the immediately prior attempt and the completed suicide: $61.55 \%$ of males and $50.0 \%$ of females changed to more lethal methods to complete the suicide, suggesting an enhanced intensity of intent. Examines the accumulation of more or less lethal methods over each of the attempts (to a maximum of five) are examined in Table 3. Overall, $80 \%$ (281/349) of all attempts were classed as less lethal- 
TABLE 2

Completed Suicides in Northern Ireland (April 2007-March 2009): Characteristics of the Type of Method Used (More Lethal vs. Less Lethal) in Both the Completed Suicide and Its Immediately Prior Attempt

\begin{tabular}{lclll}
\hline & $\begin{array}{c}\text { Last prior } \\
\text { attempt }(n)\end{array}$ & $\begin{array}{c}\text { Last prior attempt } \\
\text { classed as lethal \% }(n)\end{array}$ & $\begin{array}{c}\text { Suicide classed } \\
\text { as lethal \% }(n)\end{array}$ & $\begin{array}{c}\text { Change in method: } \\
\text { less lethal to lethal \% }(n)\end{array}$ \\
\hline Males & 117 & $20.5(24 / 117)$ & $82.1(96 / 117)$ & $61.5(72 / 117)$ \\
Females & 42 & $17.1(7 / 42)$ & $66.7(28 / 42)$ & $50.0(21 / 42)$ \\
Persons & 159 & $19.5(31 / 159)$ & $80.0(124 / 159)$ & $58.5(93 / 159)$ \\
\hline
\end{tabular}

TABLE 3

Completed Suicides in Northern Ireland (April 2007-March 2009) and Associated Counts of Prior Attempts: Characteristics of the Type of Method Used in Both the Completed Suicide and Its Associated Prior Attempts (maximum = 5)

\begin{tabular}{|c|c|c|c|c|c|c|}
\hline & \multirow{2}{*}{$\begin{array}{l}\text { No prior } \\
\text { attempts } \\
\text { recorded: } \\
\text { suicide only }\end{array}$} & \multicolumn{5}{|c|}{$\begin{array}{l}\text { Number of recorded } \\
\text { attempts occurring prior } \\
\text { to the completed suicide }\end{array}$} \\
\hline & & $\begin{array}{l}\text { One } \\
\text { attempt }\end{array}$ & $\begin{array}{c}\text { Two } \\
\text { attempts }\end{array}$ & $\begin{array}{l}\text { Three } \\
\text { attempts }\end{array}$ & $\begin{array}{c}\text { Four } \\
\text { attempts }\end{array}$ & $\begin{array}{l}\text { Five or more } \\
\text { attempts }\end{array}$ \\
\hline \multicolumn{7}{|l|}{ Persons } \\
\hline Completed suicides & 238 & 77 & 30 & 17 & 9 & 25 \\
\hline Number of attempts recorded & na & 77 & 60 & 51 & 36 & 125 \\
\hline Method: classed as lethal & 209 & 11 & 13 & 9 & 9 & 21 \\
\hline Method: classed as less lethal & 29 & 66 & 47 & 37 & 27 & 104 \\
\hline Proportion: less lethal & $12.2 \%$ & $85.7 \%$ & $78.3 \%$ & $72.5 \%$ & $75.0 \%$ & $82.4 \%$ \\
\hline \multicolumn{7}{|l|}{ Males } \\
\hline Completed suicides & 202 & 62 & 21 & 13 & 6 & 15 \\
\hline Method: classed as less lethal & 22 & 54 & 31 & 25 & 17 & 64 \\
\hline Proportion: less lethal & $10.9 \%$ & $87.1 \%$ & $78.6 \%$ & $64.1 \%$ & $70.8 \%$ & $85.3 \%$ \\
\hline$\%$ hanging & $79.4 \%$ & $8.1 \%$ & $19.5 \%$ & $20.5 \%$ & $20.8 \%$ & $5.3 \%$ \\
\hline$\%$ drugs overdose & $0.9 \%(2)$ & $69.4 \%$ & $69.1 \%$ & $59.0 \%$ & $50.0 \%$ & $85.3 \%$ \\
\hline \multicolumn{7}{|l|}{ Females } \\
\hline Completed suicides & 36 & 15 & 9 & 4 & 3 & 10 \\
\hline Method: classed as less lethal & 7 & 12 & 16 & 12 & 10 & 40 \\
\hline Proportion: less lethal & $19.4 \%$ & $80.0 \%$ & $88.9 \%$ & $100 \%$ & $80.0 \%$ & $80.0 \%$ \\
\hline$\%$ hanging & $75.0 \%$ & - & $11.1 \%$ & - & $8.3 \%$ & $2.0 \%$ \\
\hline$\%$ drugs overdose & $11.1 \%(4)$ & $66.0 \%$ & $72.2 \%$ & $91.6 \%$ & $75.0 \%$ & $80.0 \%$ \\
\hline
\end{tabular}

ranging from $72 \%$ to $85 \%$ across the groupings. While males were more likely to record a lethal attempt than females, in all groups less lethal methods comprised at least $50 \%$. This contrasts with those who died without recording a prior attempt-87\% $(209 / 239)$ used a method classed as lethal: $88 \%(180 / 204)$ and $81 \%(29 / 36)$ associated with males and females, respectively; of these, $79 \%$ and $75 \%$ were by hanging. The other major suicide method considered specifically was drug overdose; although this was the prevalent method associated with attempts, it was used in less than $1 \%$ of male and $11 \%$ of female suicides. Of the 26 persons recording at least five attempts, 15 (58\%) recorded overdoses in at least four of their five attempts. In these cases, the 
switch was mainly from (attempts using) drug overdose to completed suicide, with hanging the preferred method.

Both the known finality of lethal methods and the definitive switch in method between the final prior attempt and the completed suicide signal an apparent concentration of intent. However, this allows interest to focus on those who persist in using less lethal methods into the completed suicide - and specifically on the risks associated with those indicators marking the prior history of the deceased as they continue from attempt to completion. Table 4 records the odds ratios (ORs) associated with the use of less lethal methods in the suicide: in all models the dependent variable signifies more lethal (0) against less lethal (1) methods. Indicators included in the models were selected because they both represent known risk factors (age, gender, employment status, living alone) and, in the final model (M4), include indicators associated with prior suicide attempts. This shows that female suicides, older people, and those not living alone were more likely to use less lethal methods than their associated reference groups (M1-M4). When compared with those who had no preexisting diagnosis, persons with an assigned mental health diagnosis were also more likely to use less lethal methods in their suicide (M3) - here, the ORs associated with the summary diagnostic groups are 1.93, 4.98, and 1.38 for common mental health problems, severe mental health disorders, and alcohol/drugs problems, respectively. However, when the analysis was restricted to those with a history of prior attempts the comparable ORs almost doubled (M4). This final model (M4) also includes indicators associated with the final attempt prior to the suicide-here, those who used a less lethal method in this attempt were more likely to persist with less lethal methods at the suicide $(\mathrm{OR}=3.21: 95 \% \mathrm{CI}=0.79,13.07)$. Finally, those who had recorded two or more previous attempts were also more likely to have used less lethal methods in the suicide $(\mathrm{OR}=2.77: 95 \% \mathrm{CI}=1.06,7.23)$.

\section{DISCUSSION}

Suicide rates in Northern Ireland nearly doubled between 1995 and 2011, increasing from 8 to 15 per 100,000 of the population (NISRA, 1997-2012). This analysis explores attempted suicides associated with all completed suicides identified through coroner's records occurring over a 2-year period. Associated GP records allowed a comprehensive examination of three aspects of suicide attempts: their number, timing of the final attempt and suicide, and changing method between attempts.

The analysis explores suicide behavior over a reasonably long time frame-while all suicides occured in the 2-year window, no back limit was placed on accumulation of relevant information, especially the history of prior attempts. Our findings (consistent with the literature) suggest that men are more likely than women to use lethal methods on initial attempts or switch to them at an earlier stage-maybe implying sustained intent on their part. This tendency limits opportunities to intervene with males. For females, in this analysis, the patterns associated with their suicide behavior (and continued higher levels of use of less lethal methods) point to a lesser intensity and allow for more optimism in relation to the potential for intervention. This and other research show that these particularly vulnerable groups may be more easily identified as at continued higher risk of completing suicide (Runeson, 2002). While for males the sustained lethality of the methods used is a formidable barrier to intervention, the circumstances surrounding attempts and the presentation of these men at emergency services shortly before death suggests there may be both some unexploited opportunities for intervention and a need for sustained short-term support and outreach. This patterning of repeated "less lethality" between attempts and subsequent suicide, especially for those with preexisting diagnoses of mental health problems, may help in pinpointing the signals necessary for successful intervention (Rudd et al., 2006). 


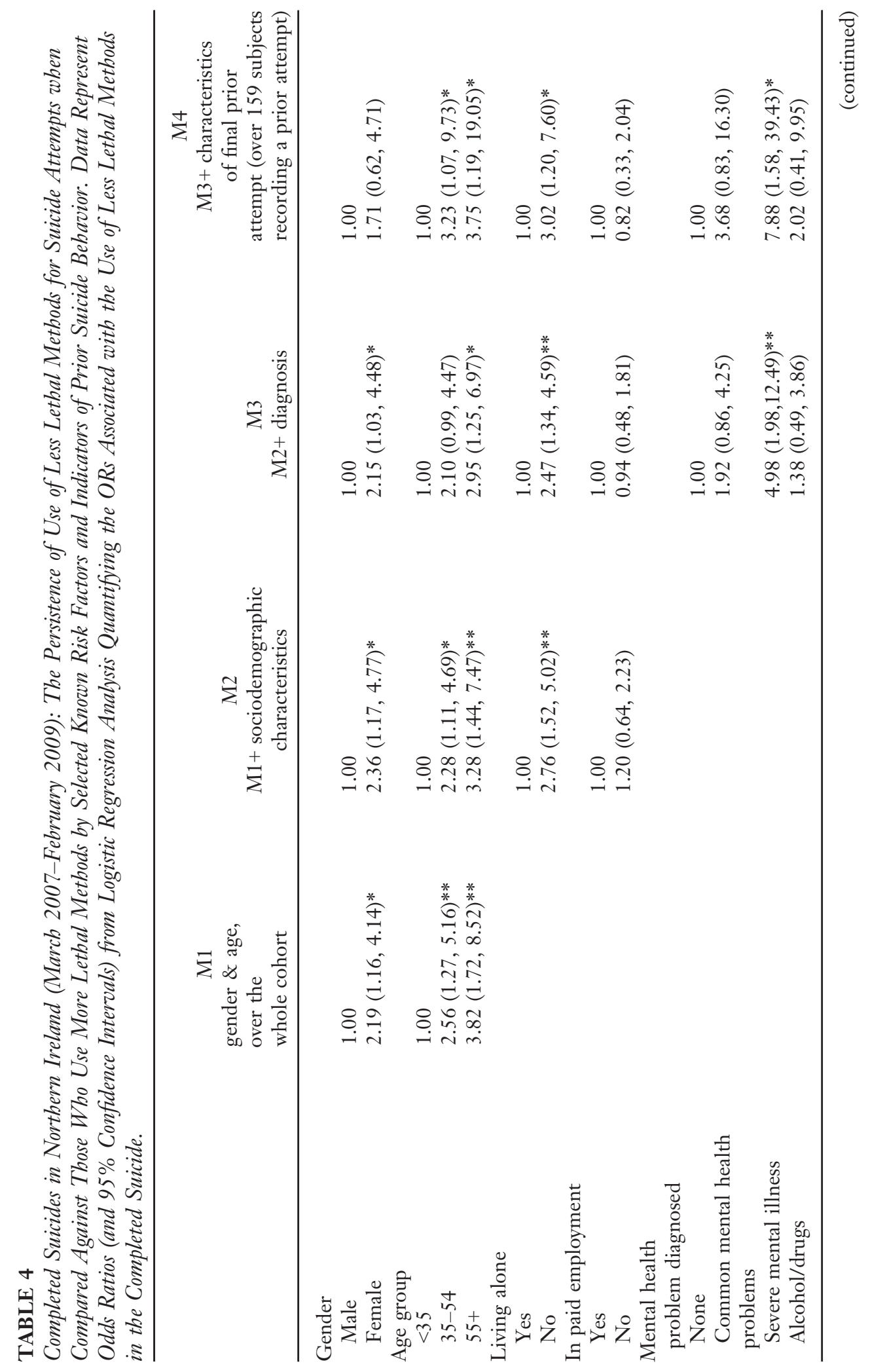




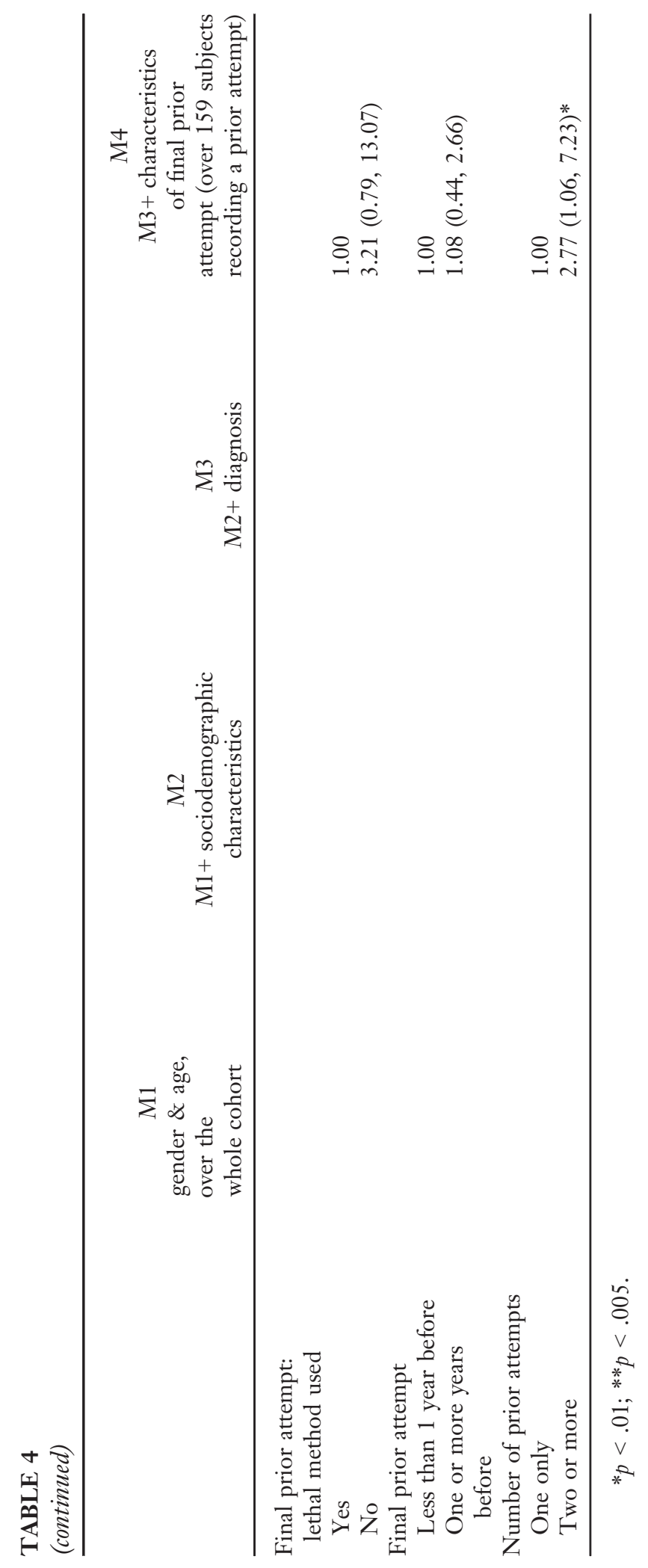


Despite the difficulties inherent in predicting repeated attempts, the important role of hospital emergency departments is recognized in the second generation of UK national programs targeting suicide prevention. Two National Institute of Health and Clinical Excellence (NICE, 2004, 2011) reports are aimed at both the short- and longer-term management and prevention of self-harm in primary and secondary care. There has been increased emphasis on practical prevention measures, and the lack of follow-up for those presenting with selfharm at emergency departments has been highlighted as a particular problem (Department of Health, 2012; McMillan, Browne, Green, \& Donnelly, 2009; Mehlum, 2004).

Surviving an attempt is not necessarily to be represented as an indication that an individual is on a pathway to a subsequent completed suicide. However, it is difficult with this data set to directly address issues of prevention, given that it comprises individuals all of whom eventually died by suicide. The death of the individuals reported on here suggests that such presentations at emergency departments are no easy route to long-term safety. For a majority of cases in this data set, survival from a prior attempt merely meant that more lethal methods were used subsequently. Nevertheless, presentation to a health professional following a suicide attempt is potentially an important step on a help-seeking pathway.

\section{REFERENCES}

Beautrais, A. C. (2004). Further suicidal behavior among medically serious suicide attempters. Suicide and Life-Threatening Behavior, 34, 1-11.

CaIne, D. (2010). Preventing suicide is hard to do! Psychiatric Services, 61(2). doi:10.1176/appi.ps.61.12.1171

Canetto, S. S., \& Cleary, A. (2012). Men, masculinities and suicidal behavior. Social Science of Medicine, 74, 461-465.

Carlsten, A., Waern, M., Ekedahl, A., \& Ranstam, J. (2001). Antidepressant medication and suicide in Sweden. Pharmacoepidemiology \& Drug Safety, 10, 525-530.
Detailed accounts of lifetime patterning of help-seeking in relation to suicide attempts are poorly reported in the literature, and we thus have limited understanding of both how health and social care systems manage potential suicide cases and how this might influence subsequent engagement with healthcare services. Further research is needed on how people who attempt suicide are assessed and responded to in hospital emergency settings and the factors that influence subsequent help-seeking.

\section{LIMITATIONS}

There are some limitations to the data. While medical records were not available for $10 \%$ of the cohort, a sensitivity analysis showed no bias in terms of age or gender. Neither of these data sources were originally designed to study attempted suicide, and completeness of the record is reliant on (1) the person making the attempt seeking medical attention, and (2) effective communication between emergency departments and general practitioners. It is therefore possible that recorded attempts can underestimate the true burden of attempted suicide. However, there are strengths to this approach - the records capture only those events serious enough to warrant presentation to a medical practitioner, and these provide opportunities for intervention.
Carter, G., Reith, D., Whyte, I., \& McPherson, M. (2005). Repeated self-poisoning: Increasing severity of self-harm as a predictor of subsequent suicide. British Fournal of Psychiatry, 186, 253-257.

Cederecke, M., \& Ojehagen, A. (2005). Prediction of repeated parasuicide after 1-12 months. European Psychiatry, 20, 101-110.

Cullberg, J., Wasserman, D., \& SteFansson, C. G. (1988). Who commits suicide after a suicide attempt? An 8 to 10 year follow up in a suburban catchment area. Acta Psychiatrica Scandinavica, 77, 598-603. 
Department of Health, Mental Health and Disability Division. (2012). Preventing suicide in England - A cross-government outcomes strategy to save lives. London: Author.

Harvard School of Public Health. (2013). Lethality of suicide method. Retrieved September 9, 2013, from http://www.hsph.harvard.edu/ means-matter/means-matter/case-fatality/.

IsOmetsa, E., \& LonNQuist, J. K. (1998). Suicide attempts preceding completed suicides. British Fournal of Psychiatry, 173, 531-535.

Kerkhof, A. J. F. M., Schmidtke, A., Bille-Brahe, U., \& Lonnqvist, J. (eds). (1994). Attempted suicide in Europe: Findings from the multicentre study on parasuicide by the WHO Regional Office for Europe. Leiden: DSWO Press.

Laje, G., Paddock, S., Manji, H., Rush, J., Wilson, A., Charney, D., ET AL. (2007). Genetic markers of suicidal ideation emerging during citalopram treatment of major depression. The American Fournal of Psychiatry, 164, 1530 1538.

Lewis, G., \& Sloggett, A. (1998). Suicide, deprivation, and unemployment: Record linkage study. British Medical fournal, 317, 1218-6.

MARIS, R. (1992). How are suicides different? In R. W. Maris, A. L. Berman, J. T. Maltsberger, \& R. I. Yufit (Eds.), Assessment and prediction of suicide (pages 65-87). New York: Guilford.

Maris, R. W., Berman, A. L., \& SilverMAN, M. S. (2000). Comprehensive textbook of suicidology. New York: Guilford.

McMillan, F. V., Browne, N., Green, S., \& Donnelly, D. (2009). A card before you leave: Participation and mental health in Northern Ireland. Health and Human Rights, 11, 61-72.

MenLum, L. (2004). A suicide prevention strategy for England. Crisis, 25, 69-73.

Mok, P. L. H., Kapur, N., Windfuhr, K., Leyland, A., Appleby, L., Platt, S., et al. (2012). Trends in national suicide rates for Scotland and England \& Wales, 1960-2008. British Fournal of Psychiatry, 200, 245-251.

Moser, K., Fox, A. J., \& Jones, D. R. (1984). Unemployment and mortality in the OPCS longitudinal study. Lancet, 323, 1324 1329.

Murphy, T. M., Mullins, N., Ryan, M., Foster, T., Kelly, C., McClelland, R., ET al. (2013). Genetic variation in DNMT3B and increased global DNA methylation is associated with suicide attempts in psychiatric patients Genes, Brain and Behavior, 12, 125-132.

National Institute for Health and Care Excellence. (2004). Self-harm: The short-term physical and psychological management and secondary prevention of self-harm in primary and secondary care. [Clinical Guideline 16]. London: Author.

National Institute for Health and Care Excellence. (2011). Self-harm: Longer term management [Clinical Guideline 133]. London: Author

NISRA. Suicide death rates by sex, 19972012. Retrieved September 15, 2009, from http://www.nisra.gov.uk/demography/default.asp3 1.htm.

Oquendo, M. A., Friend, J. M., Halberstam, B., Brodsky, B. S., Burke, A. K., GruneBaum, M. F., ET AL. (2003). Association of comorbid posttraumatic stress disorder and major depression with greater risk for suicidal behavior. American Journal of Psychiatry, 160, 580-582.

O'Reilly, D., Rosato, M., Connolly, S., \& Cardwell, C. (2008). Area factors and suicide: 5-year follow-up of the Northern Ireland population. British Fournal of Psychiatry, 192, 106-111.

Owens, D., Horrocks, J., \& House, A. (2002). Fatal and non-fatal repetition of selfharm: Systematic review. British Journal of Psychiatry, 181, 193-199.

Rudd, M. D., Berman, A. L., Joiner, T. E., Nock, M. K., Silverman, M. M., Mandrusiak, M., ET AL. (2006). Warning signs for suicide: Theory, research, and clinical applications. Suicide and Life-Threatening Behavior, 36, 255.

Runeson, B. S. (2002). Suicide after parasuicide. British Medical fournal, 325, 11251126.

Runeson, B., Tidemalm, D., Dahlin, M., Lichenstein, P., \& Langstrom, N. (2010). Method of attempted suicide as predictor of subsequent suicide: National long term cohort study. British Medical fournal, 340, c3222.

Shiner, M., Scourfield, J., Fincham, B., \& LANGER, S. (2009). When things fall apart: Gender and suicide across the life course. Social Science of Medicine, 69, 738-746.

Wheller, L., Baker, A., Griffiths, C., \& Rooney, C. (2007). Trends in avoidable mortality in England and Wales, 1993-2005. Health Statistics Quarterly, 34, 6-25.

Williams, M. (1997). Cry of pain: Understanding suicide and self-harm. London: Penguin Books.

Manuscript Received: April 11, 2014

Revision Accepted: August 5, 2014 